\title{
Author Correction: Ventral tegmental area GABAergic inhibition of cholinergic interneurons in the ventral nucleus accumbens shell promotes reward reinforcement
}

Ream Al-Hasani (D), Raajaram Gowrishankar, Gavin P. Schmitz, Christian E. Pedersen, David J. Marcus, Sofia E. Shirley, Taylor E. Hobbs (D), Abigail J. Elerding, Sophie J. Renaud, Miao Jing, Yulong Li (D), Veronica A. Alvarez (D), Julia C. Lemos and Michael R. Bruchas (iD

Correction to: Nature Neuroscience https://doi.org/10.1038/s41593-021-00898-2, published online 12 August 2021

In the version of this Article initially published, the Acknowledgements section omitted to include the following: "NARSAD Young Investigator Grant from the Brain and Behavior Research Foundation, grant no. 28243 (to R.A.-H.)." This grant has now been included.

The original Article has been corrected in the online version of the paper.

Published online: 9 September 2021

https://doi.org/10.1038/s41593-021-00928-z

๑ The Author(s), under exclusive licence to Springer Nature America, Inc. 2021 